\title{
Study of Success levels and Success Criteria for Infrastructure Projects in Thiruvananthapuram
}

\author{
Sarosh Kothandath, Hari Haran
}

\begin{abstract}
Public Infrastructure projects are generally believed to be complex and success rates of these projects are reported as far from satisfactory. Advances in project management techniques over the yearsdoes not effectively address the success gap, the subjective nature of what constitutes project success adds more to the uncertainty. Public projects utilize public funds and hence has the accountability towards public opinion and are expected to generate positive public appeal from the users. This paper intends to discover the opinion of project users in Thiruvananthapuramcity on success criteria for infrastructure projects and to conduct a comparative analysis for transport and water sector projects as well as comparison of user and project professional viewpoints on project success for both these sectors
\end{abstract}

Keywords: Infrastructure, Project success, Success Criteria, User preference

\section{INTRODUCTION}

Infrastructure serves to cater the human needs of the native community and its development is often guided by regional preferences. Influence of regional character is felt in the progress and performance of infrastructure projects, especially public projects. Infrastructure projects in the Kerala context are observed to be slow moving and success rates are not very satisfactory. Projects getting pre-closed, project assets getting obsolete or assets remaining partly functional or non-functional is found to be common pointing to possible failures due to a variety of reasons. Success of field under various perspectives. Project success is subjective since different stakeholders have varying views. In the words of Lipovetsky et al., "the assessment of a project's success may differ depending on the point of view of the person who is asked to provide the assessment"[1] whereas Bannerman notes that "success is perceptual, and perceptions vary with the stakeholder's perspective and the passage of time since project completion"[2].Ika describes that "The classification of a project as a success or a failure is, to a degree, subjective"[3]. Muller and Jugdev adds "project success as "predominately in the eyes of the beholder" meaning one stakeholder may consider a project successful, where another stakeholder would consider it a failure"[4]. This paper studies projects in two important public infrastructure sectors viz., transport and water sectorsfrom the viewpoint of project users.

\section{A. Project Success and Project Management Success}

Success of projects is a widely researched topic since

Revised Manuscript Received on July 05, 2020.

* Correspondence Author

Studies, ICFAI University Jharkhand, Ranchi, India. E-mail:

saroshmenon@gmail.com

Dr. Hari Haran, Adjunct Professor, Faculty of Management Studies,

ICFAI University Jharkhand, Ranchi, India E-mail: harimti@hotmail.com projects in various fields continues to be a major research

Sarosh Kothandath*, Research Scholar, Faculty of Management

decades, early studies during seventies to eighties considered project success in terms of achievement of management factors. Baker, Fischer and Murphy differentiatedfactors based on whether they lead to success or cause failure [5]. The project management concept in early days focused on timely completion, near the budget cost and deigned performanceto rate a project as successful. Client satisfaction and similar factors came into prominence later[6].Atkinson referred to the project management criteria as "iron triangle" comprising cost, time and quality[7]. Researchers like de Wit, Munns and Bjermi differentiated project success and project management success and pointed out that an overall project management process is not sufficient for a successful project whereas poor project management performance alone will not mean that the project failed[8-9]. Jugdev and Thomas explained that project success is a multidimensional construct and is inclusive of both short-term results affecting project management success and the longer-term achievement of desired results like effectiveness and impact.[10].Baccarini views that "Project management success is measured in terms of internal factors (cost-time-quality) whereas achieving product success is concerned with project's external effectiveness"[11].Project management success is a subset of project successand hence delivering project success is more difficult than delivering project management success, referError! Reference source not found..Project Management success is measured with initially fixed goals whereas as the project progresses, methods and focus may need realignment and this will affect the project success[12].

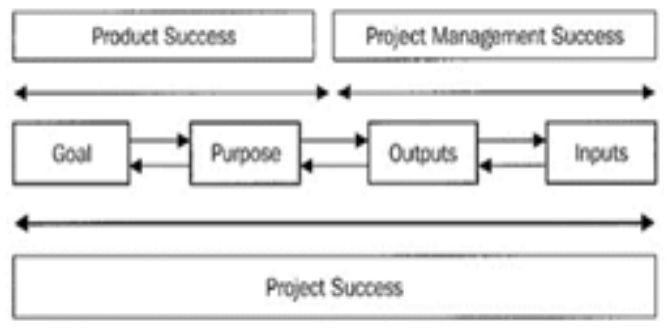

Fig 1: Project Management Success as a subset of Project success, used from [11]

\section{B. Success Criteria and Success factors}

Morris and Hough define success criteria as "the measures used to judge the success or failure of a project; these are dependent variables that measure success"[13]. Success Criteria as measuresfor success assessment of projects includes both tangible and intangible criteria. As per Cooke-Davies, "Success criteria refer to the measurement of project success whereas success factors refer to the those inputs to management system that lead directly/ indirectly to the success of project/ business"[12].

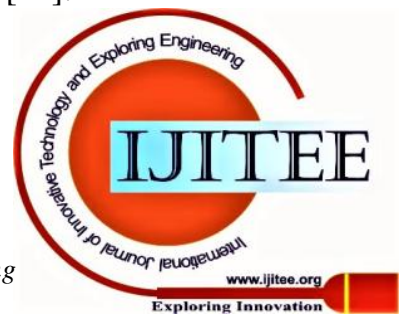


Baccarini adds that "Hard factors like cost, time, quality is relatively easy to measure. Soft factors like happiness, job satisfaction, enhanced reputation are subtle and difficult to measure"[11].

A review of past research on success of projects and related criteria shows criteria suiting all projects is hard to find.Wateridge states that "Success criteria will differ from project to project depending on a number of issues, for example, size, uniqueness and complexity"[14]. Hussein categorisesstudies on project success criteria from literature into three major groups -success criteria grouping, rationale behind these criteria and risk factors linkedtosuch criteria[15]. According to deWit, "The most appropriate criteria for success are the project objectives. The degree to which these objectives have been met determine the success of the project"[8]. Multiple project objectives and multiple project stakeholders increases the complexity of the issue. Importance for success criteria varies along the project life cycle as with the criteria itself. Quoting de Wit again, "The emphasis on what is important in a project, changes from one phase of the project to the next"[8]. Further, Shenhar and Wideman studied different stages of project and classifies them as "Internal Project Objectives (Pre-completion), Benefit to Customer (Short term), Direct Contribution (Medium term) and Future Opportunity (Long term) with multiple criteria under each category"[16].

\section{Project Stakeholders and success perceptions}

Success of project is viewed differently by various stakeholders[17]. While evaluating project management effort cost, time and quality performance could possibly be good enough whereas to judge project success, the objectives of all stakeholders along the project life cycle and stakeholders at different levels of hierarchy need to be examined[8]. Laroche studied the cultural aspects of international projects and warned that "Differences in approaches, values and expectations between customers, suppliers and team members with different cultural backgrounds have led to many project failures"[18]. The choice or preference for success criteria even for same type of projects shows variations due to many subjective factors like cross cultural differences, beliefs, values etc.It needs to be understood that expectations of various stakeholders about the project outcome and its fulfilment also plays a role in their respective opinions on success. Perceptions and expectations of different stakeholders as well as the assessment time also thus assumes special importance[8].

\section{STUDY AREA AND OBJECTIVE}

Infrastructure projects in Thiruvananthapuram city, the capital of Kerala State in India is studied.

The objectives of this study are:

- To obtain user rating for success of infrastructure projects in Thiruvananthapuram.

- To explore user views on criteria for success of projects and identify important success criteria.

- To examine the impact of preference for success criteria on success rating of the above projects.

\section{HYPOTHESES}

$\mathrm{H}_{1}$ - Success rating for Transport and Water projects are relatively similar.

$\mathrm{H}_{1 \mathrm{~A}}-$ Success Rating for Transport and Water Projects are significantly different

$\mathrm{H}_{2}$ - Success rating for projects by Users and project professionals are similar.

$\mathrm{H}_{2 \mathrm{~A}}$ - Success rating for projects by Users varies significantly from that of project professionals.

$\mathrm{H}_{3}$-Preference level for success criterion is unrelated to the success rating

$\mathrm{H}_{3 \mathrm{~A}}$ - Preference level for success criterion and success rating are significantly related

\section{METHODOLOGY AND ANALYSIS}

Survey of project users on the success rating of projects and preference rating for the various criteria considered in evaluating each of the projects is collected. The survey questionnaire was divided into different sections:

- Demographic information on the respondents including sector familiarity and involvement in infrastructure projects

- $\quad$ Project Familiarity, Success Rating and Success Criteria

- Project Success Factors (not part of this paper)

The analysis framework comprises a set of thirteen project success criteria obtained from literature and from pilot survey/ researchers own information. Table Ibelow gives the thirteen success criteria used in this study and the reference literature source for each. A total of six projects are covered (3 transport projects and 3 water projects) in the analysis, Table II gives the project particulars. The questionnaire enables respondents to select their project familiarity level, success rating, level of preference for each of the thirteen success criteria for each of the six projects. Success criteria are given qualitative rating (5-point Likert scale) for its 'level of preference'.An analysis of Indian executives onproject success criteria was reported in earlier studies [19]. Analysis of the household survey data with respect to success rating and success criteria for transport and water infrastructure projects in Thiruvananthapuram is included in this paper. Comparative analysis of project success rating and success criteria for the sectors as well as comparative analysis of success rating by users and other stakeholders is carried out and the analysis results presented here.

Table I: Success Criteria from literature used

\begin{tabular}{|c|c|}
\hline $\begin{array}{c}\text { Project Success Criteria and Corresponding } \\
\text { (Variable name) }\end{array}$ & Reference Source \\
\hline $\begin{array}{c}\text { Timely Completion } \\
\text { (Time) }\end{array}$ & {$[16],[7]$} \\
\hline $\begin{array}{c}\text { Within Project budget } \\
\text { (Budget) }\end{array}$ & {$[16],[7],[8],[20]$} \\
\hline $\begin{array}{c}\text { (ExpBen) } \\
\text { (InfQua) }\end{array}$ & {$[17][21]$} \\
\hline $\begin{array}{c}\text { Quality of Finished Infrastructure } \\
\text { (USatis) }\end{array}$ & {$[116],[7],[8],[22]$,} \\
\hline $\begin{array}{c}\text { Good User Satisfaction (Customer satisfaction) } \\
\text { Published By: } \\
\text { Blue Eyes Intelligence Engineering } \\
\text { and Sciences Publication }\end{array}$
\end{tabular}




\begin{tabular}{|c|c|}
\hline $\begin{array}{c}\text { Project Success Criteria and Corresponding } \\
\text { (Variable name) }\end{array}$ & Reference Source \\
\hline $\begin{array}{c}\text { Use of new/ improved/innovative technology } \\
\text { (NuTek) }\end{array}$ & {$[16],[22]$} \\
\hline $\begin{array}{c}\text { Improved service delivery after project } \\
\text { (ImpSer) }\end{array}$ & {$[23]$} \\
\hline $\begin{array}{c}\text { Less Public Disturbance during work } \\
\text { (PuDist) }\end{array}$ & {$[7]$} \\
\hline $\begin{array}{c}\text { No adverse impact on society and surroundings } \\
\text { (AdvImp) }\end{array}$ & {$[2]$} \\
\hline $\begin{array}{c}\text { Good Public interaction during project } \\
\text { (PuCons) }\end{array}$ & {$[11]$} \\
\hline $\begin{array}{c}\text { Ease of Access/Use } \\
\text { (EazUse) }\end{array}$ & {$[7]$} \\
\hline $\begin{array}{c}\text { Lower Usage Cost } \\
\text { (UsCost) }\end{array}$ & \\
\hline $\begin{array}{c}\text { Social Responsibility } \\
\text { (SocResp) }\end{array}$ & \\
\hline
\end{tabular}

Table II: Project Particulars

\begin{tabular}{|l|l|l|}
\hline S.No & Code & Project Name \\
\hline 1 & P1 & Karamana- Kaliyikkavila NH project \\
\hline 2 & P2 & Thiruvananthapuram City Roads Improvement Project \\
\hline 3 & P3 & Thampanoor Bus Terminal (KTDFC) \\
\hline 4 & P4 & JICA water supply Project (KWA) \\
\hline 5 & P5 & Muttathara Sewage Treatment Plant \\
\hline 6 & P6 & Operation Anantha \\
\hline
\end{tabular}

\section{A. Sample size and Sampling Methodology}

Thiruvananthapuram city has a total areal extent of 236 sq. $\mathrm{km}$ and a population of about 10 lakhs. The city area is divided into 100 administrative wards which includes the densely populated central city area and peripheral areas of relatively less density. Sample size is computed based on the Cochran's formula[24] as given below:

$$
n_{o}=\frac{Z^{2} p q}{e^{2}}
$$

$\mathrm{n}_{0}$ is sample size, $\mathrm{Z}$ value is obtained from normal curve for respective $\alpha$ values, $1-\alpha$ is the confidence level, e is level of precision, $\mathrm{p}$ is estimated proportion of attributes in population, and $\mathrm{q}$ is $1-\mathrm{p}$.

Multi-level clustered sampling approach was followed for the survey. The city area is divided into three density clusters based on population density as HIGH, MEDIUMand LOW. A total of 7 wards were selected out of the total 100 wards as first level with 4 wards from HIGH density cluster, 2 wards from MEDIUM density cluster and 1 ward from LOW density cluster. Each ward is divided into minimum five to maximum eight electoral booths depending upon ward population. One booth from each selected ward is chosen for the second level. From the selected booths, households are randomly selected for the survey. The total sample size is 506. A map of Thiruvananthapuram city with the density clusters and selected wards is included in Fig.2 and ward wise sample details included in Table III.

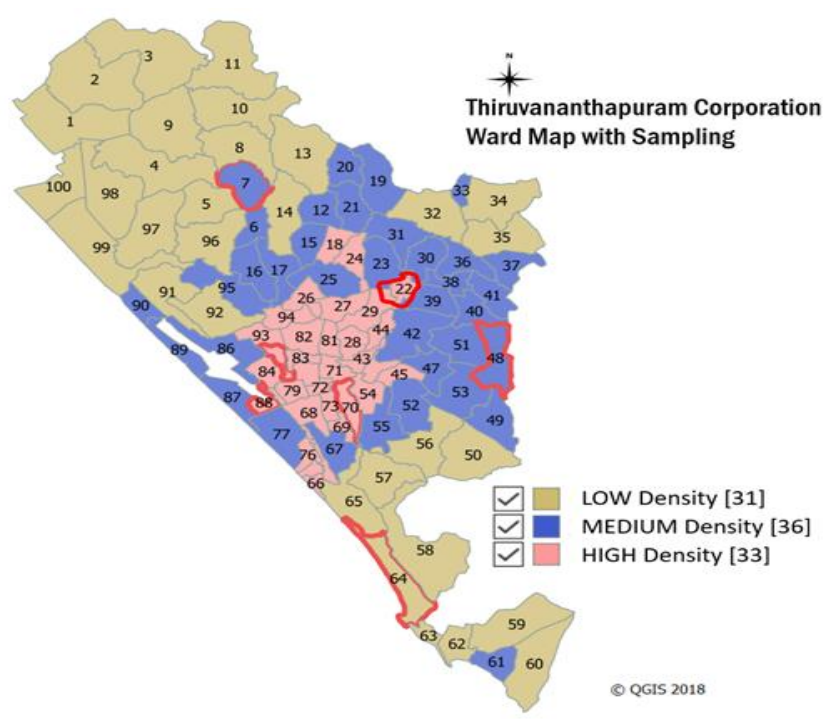

Fig.2: Thiruvananthapuram City Map and Clustering

Table III: Sampling Details

\begin{tabular}{|l|l|l|l|}
\hline Ward No. & Ward Name & Samples & Cluster \\
\hline 22 & Sasthamangalam & 75 & \multirow{2}{*}{ HIGH } \\
\hline 70 & Attukal & 75 & \\
\cline { 1 - 2 } & Palkulangara & 75 & \\
\cline { 1 - 2 } & Vallakadavu & 75 & \multirow{2}{*}{ MEDIUM } \\
\cline { 1 - 2 } & Edavacode & 56 & \\
\hline 48 & Thrikkannapuram & 75 & LOW \\
\hline 64 & Vellar & 75 & \\
\hline
\end{tabular}

\section{B. Screening by Project Familiarity of respondents}

Familiarity of the respondents for each project is collected on 5-point Likert scale (rating from minimum 1 to maximum 5). Users with lower project familiarity ratings of 1 and 2 for each project were screened out from the analysis to make sure that the analyzed data corresponds to users with sufficient familiarity with the projects under study. Rating for each project is considered as separate response in the analysis thereby the total number of samples is 2260 .

\section{Association of Criteria to Success rating}

The study uses descriptive statistics, different methods of correlation analysis and hypothesis testing. Scale reliability along with reliability for individual variables is checked.The level of association between Success rating and each of the individual success criteria rating is analyzed by computing the correlation coefficients and checking significance. Spearman's rho and Kendall's Tau values are computed in JASP software[25].

\section{Polyserial Correlation}

Polyserial correlation is used for association between a continuous and a categorical (ordinal) variable as defined by Olsson, Drasgow, and Doransin [26],"...the case where one observed variable is polychotomous and ordinal, and the other observed variable is continuous. The product moment correlation between these observed variables is called the point polyserial correlation...".

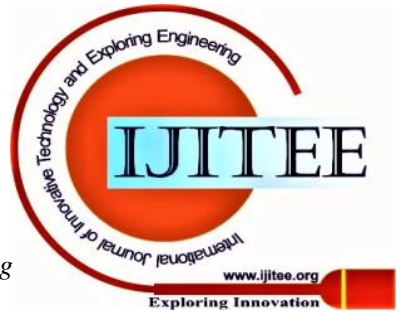


Polyserial coefficients for the variable pairs are computed using LISREL 10.20 package[27]. Ordinal factor analysis of the success criteria importance scores isattempted using LISREL to identify any underlying latent variable. However, presence of any latent variable could not be detected.

\section{RESULTS AND DISCUSSION}

Success rating for each of the individual projects is collected as a percentage and rating for preference of success criteria is on a 5- point Likert scale. Statistical analysis is carried out using JASP Ver 12.1 and LISREL 10.20 software packages. Reliability of scale for the success criteria is checked, the Cronbach $\alpha$ coefficient obtained is 0.762 and McDonalds $\omega$ is 0.763 which is satisfactory. Descriptive Statistics for the success rating are given in Table IV.

Normality check for the variables is carried out using Shapiro-Wilk test, the values are above 0.9 with significance level $<0.01$ indicating clear deviation from normality.

\section{A. Success Rating for Transport Vs Water Projects}

Hypothesis1 on success rating of projects for individual sectors is tested by conducting the Independent samples $\mathrm{T}$ Test and computing Welch statistic. Considering deviation from normality, unequal sample sizes and difference in variance, Mood's Median test[28] is also conducted, the test results are shown below in Table $\mathbf{V}$. Both the test statistic shows significant evidence to reject the null hypothesis. User Success rating for Transport projects in Thiruvananthapuram is found to be greater than that of Water projects.

\section{B. Success Rating for Users Vs Project Professionals}

Test for Hypothesis2is conducted by combining success rating for both transport and water sector projects. Respondents with involvement in infrastructure projects in any capacity were separated out and compared. Test results are presented in Table VI.Calculated chi-square value is less than the critical value for 0.1 significance level,hence no sufficient evidence to reject the null hypothesis. In other words, project success rating for users and project professionals are similar.

Table IV: Success Rating - Descriptive Statistics

\begin{tabular}{|l|l|l|l|}
\hline Statistic & All Projects & Transport & Water \\
\hline Sample Size & 2260 & 1451 & 809 \\
\hline Missing & 1 & 0 & 1 \\
\hline Mean & 50.16 & 54.09 & 43.11 \\
\hline Std. Deviation & 15.58 & 13.88 & 15.99 \\
\hline Shapiro-Wilk & 0.965 & 0.96 & 0.953 \\
\hline P-value of Shapiro-Wilk & $<.001$ & $<.001$ & $<.001$ \\
\hline
\end{tabular}

Table V: Hypothesis1- Testing Success Rating for sector

\begin{tabular}{|c|c|c|c|}
\hline Test & Statistic & df & p \\
\hline Mood's Median test & 95.28 & 1 & $<0.01$ \\
\hline Welch & 16.384 & 1484.257 & $<.001$ \\
\hline
\end{tabular}

Table VI: Hypothesis2-Testing Success Rating for Stakeholder

\begin{tabular}{|c|c|c|c|}
\hline Test & Statistic & df & p \\
\hline Mood's Median test & 1.54 & 1 & $>0.1$ \\
\hline Welch & -2.17 & 134.03 & 0.032 \\
\hline
\end{tabular}

\section{Success Criteria and Success ratingrelation}

Relation between success criteria preference level on a 5 -point Likert scale and project success rating is checked by computing the correlation coefficients.

Table VII shows the correlation coefficients computed for each success criteria preference level to the project success rating for the transport and water projects combined. Kendall's tau is computed using both classical method and Bayesian analysis whereas Classical Spearman's rho is computed, the respective significance factor and Bayesian factors obtained in JASP are shown in the table. Polyserial correlation coefficient is computed in LISREL. Correlation coefficients show significant association for all the success criteria with coefficients below 0.25 . Among the 13 success criteria, four criteria (Time, Budget, Expected Benefits and New Technology) show relatively bigger correlation coefficient values between 0.2 and 0.25 indicating a stronger association with the project success levels. Of the thirteen success criteria, nine criteria show significance level below 0.001 whereas the remaining criteria show correlation significance levels below 0.05 and hence correlation coefficients for all success criteria are acceptable.

\section{Comparison of Transport and Water Sectors}

Separate analysis is conducted for the transport and water sector projects to identify the relation between project success rating to success criteria preferences specific to that sector and to identify similarities/ differences between the sectors. Conventional correlation coefficients (Spearman and Kendall) and polyserial coefficients are computed for each sector, comparison of sector wise details given in Table VIII.

On comparing the three coefficients (Kendall, Spearman and Polyserial), we observed that the significance level for Polyserial correlation coefficient shows more variation in comparison to both Spearman's rho and Kendall's tau. Whereas the significance levels of Spearman's and Kendall's coefficients are below 0.01 for all criteria for both the sectors, there is significant variation in significance levels for Polyserial coefficient. However, considering that our dependent variable viz., Project success rating is continuous scalar variable and the independent variable viz., success criteria preference level is in Likert scale, we attach more importance to the polyserial coefficient values. Correlation coefficient values for the transport sector are relatively smallshowing weak correlation withfive of the criteria showing significance below 0.03 whereas the remining eight factors have significance values above 0.09 . In the case of water sector, correlation coefficients are comparatively bigger ranging from 0.12 to 0.26 with seven criteria having significance levels below 0.03 and balance eight with level of significance above 0.075 .In the case of transport projects, Ease of Use and Public consultation are having maximum relation to project success whereas for water projects Time, Budget, Usage Cost and No Adverse impact shows more relation to success. 
Table VII: Correlation coefficients - All Projects

\begin{tabular}{|c|c|c|c|c|c|c|c|}
\hline \multirow{2}{*}{ Success Criteria } & \multicolumn{3}{|c|}{ Kendall } & \multicolumn{2}{|c|}{ Spearman } & \multicolumn{2}{|c|}{ Polyserial } \\
\hline & tau B & p & $\mathbf{B F}_{10}$ & rho & $\mathbf{p}$ & Correlation & p \\
\hline Time & 0.189 & $<.001$ & $5.245 \mathrm{e}+37$ & 0.241 & $<.001$ & 0.249 & $<.001$ \\
\hline Budget & 0.176 & $<.001$ & $5.256 \mathrm{e}+32$ & 0.225 & $<.001$ & 0.243 & $<.001$ \\
\hline ExpBen & 0.177 & $<.001$ & $6.004 \mathrm{e}+32$ & 0.228 & $<.001$ & 0.238 & 0.009 \\
\hline InfQua & 0.143 & $<.001$ & $1.258 \mathrm{e}+21$ & 0.185 & $<.001$ & 0.203 & $<.001$ \\
\hline USatis & 0.118 & $<.001$ & $7.260 \mathrm{e}+13$ & 0.152 & $<.001$ & 0.164 & 0.001 \\
\hline NuTek & 0.177 & $<.001$ & $1.341 \mathrm{e}+33$ & 0.226 & $<.001$ & 0.240 & 0.002 \\
\hline ImpSer & 0.13 & $<.001$ & $9.141 \mathrm{e}+16$ & 0.167 & $<.001$ & 0.182 & $<.001$ \\
\hline PuDist & 0.12 & $<.001$ & $2.340 \mathrm{e}+14$ & 0.155 & $<.001$ & 0.169 & 0.001 \\
\hline AdvImp & 0.123 & $<.001$ & $1.730 \mathrm{e}+15$ & 0.16 & $<.001$ & 0.165 & $<.001$ \\
\hline PuCons & 0.142 & $<.001$ & $3.858 \mathrm{e}+20$ & 0.183 & $<.001$ & 0.190 & 0.014 \\
\hline EazUse & 0.138 & $<.001$ & $3.406 \mathrm{e}+19$ & 0.177 & $<.001$ & 0.189 & $<.001$ \\
\hline UsCost & 0.124 & $<.001$ & $3.087 \mathrm{e}+15$ & 0.159 & $<.001$ & 0.175 & $<.001$ \\
\hline SocResp & 0.091 & $<.001$ & $3.642 \mathrm{e}+7$ & 0.119 & $<.001$ & 0.130 & 0.022 \\
\hline
\end{tabular}

Table VIII: Correlation Coefficients - Transport and Water Projects

\begin{tabular}{|c|c|c|c|c|c|c|c|c|}
\hline \multirow{2}{*}{ Success Criteria } & \multirow{2}{*}{ Sector } & \multicolumn{3}{|c|}{ Kendall } & \multicolumn{2}{|c|}{ Spearman } & \multicolumn{2}{|c|}{ Polyserial } \\
\hline & & tau B & $\mathbf{p}$ & $\mathrm{BF}_{10}$ & rho & $\mathbf{p}$ & Correlation & P-Value \\
\hline \multirow{2}{*}{ Time } & Transport & 0.107 & $<.001$ & $4.620 \mathrm{e}+6$ & 0.135 & $<.001$ & 0.138 & 0.232 \\
\hline & Water & 0.189 & $<.001$ & $5.458 \mathrm{e}+12$ & 0.243 & $<.001$ & 0.237 & 0.001 \\
\hline \multirow{2}{*}{ Budget } & Transport & 0.088 & $<.001$ & 8943.46 & 0.108 & $<.001$ & 0.11 & 0.659 \\
\hline & Water & 0.162 & $<.001$ & $1.070 \mathrm{e}+9$ & 0.211 & $<.001$ & 0.204 & 0.002 \\
\hline \multirow{2}{*}{ ExpBen } & Transport & 0.09 & $<.001$ & 18178.316 & 0.115 & $<.001$ & 0.121 & 0.151 \\
\hline & Water & 0.168 & $<.001$ & $5.513 \mathrm{e}+9$ & 0.217 & $<.001$ & 0.204 & 0.093 \\
\hline \multirow{2}{*}{ InfQua } & Transport & 0.058 & 0.006 & 7.627 & 0.073 & 0.005 & 0.088 & 0.001 \\
\hline & Water & 0.108 & $<.001$ & 1617.482 & 0.141 & $<.001$ & 0.145 & 0.126 \\
\hline \multirow{2}{*}{ USatis } & Transport & 0.038 & 0.069 & 0.34 & 0.047 & 0.071 & 0.063 & 0.011 \\
\hline & Water & 0.118 & $<.001$ & 13543.856 & 0.151 & $<.001$ & 0.14 & 0.474 \\
\hline \multirow{2}{*}{ NuTek } & Transport & 0.091 & $<.001$ & 24269.318 & 0.115 & $<.001$ & 0.105 & 0.671 \\
\hline & Water & 0.201 & $<.001$ & $3.047 \mathrm{e}+14$ & 0.258 & $<.001$ & 0.26 & 0.078 \\
\hline \multirow{2}{*}{ ImpSer } & Transport & 0.049 & 0.017 & 1.743 & 0.063 & 0.016 & 0.076 & 0.157 \\
\hline & Water & 0.113 & $<.001$ & 4644.008 & 0.144 & $<.001$ & 0.139 & 0.001 \\
\hline \multirow{2}{*}{ PuDist } & Transport & 0.075 & $<.001$ & 345.15 & 0.096 & $<.001$ & 0.094 & 0.091 \\
\hline & Water & 0.1 & $<.001$ & 364.681 & 0.13 & $<.001$ & 0.124 & 0 \\
\hline \multirow{2}{*}{ AdvImp } & Transport & 0.045 & 0.029 & 0.918 & 0.057 & 0.03 & 0.056 & 0.24 \\
\hline & Water & 0.181 & $<.001$ & $3.997 \mathrm{e}+11$ & 0.238 & $<.001$ & 0.226 & 0 \\
\hline \multirow{2}{*}{ PuCons } & Transport & 0.081 & $<.001$ & 1548.541 & 0.104 & $<.001$ & 0.102 & 0.007 \\
\hline & Water & 0.128 & $<.001$ & 129557.866 & 0.167 & $<.001$ & 0.153 & 0.358 \\
\hline \multirow{2}{*}{ EazUse } & Transport & 0.087 & $<.001$ & 6805.218 & 0.111 & $<.001$ & 0.119 & 0.03 \\
\hline & Water & 0.11 & $<.001$ & 2402.64 & 0.141 & $<.001$ & 0.124 & 0.028 \\
\hline \multirow{2}{*}{ UsCost } & Transport & 0.025 & 0.226 & 0.094 & 0.031 & 0.242 & 0.018 & 0.002 \\
\hline & Water & 0.16 & $<.001$ & $5.353 \mathrm{e}+8$ & 0.206 & $<.001$ & 0.227 & 0.011 \\
\hline \multirow{2}{*}{ SocResp } & Transport & 0.022 & 0.291 & 0.073 & 0.028 & 0.291 & 0.038 & 0.974 \\
\hline & Water & 0.098 & $<.001$ & 287.52 & 0.131 & $<.001$ & 0.134 & 0.169 \\
\hline
\end{tabular}




\section{Study of Success levels and Success Criteria for Infrastructure Projects in Thiruvananthapuram}

Hypothesis 3 on the lack of relation between success criteria preference level and project success rating could not be adequately rejected. Since the relation with success rating does not hold good for all criteria while using sector-wise project data, it is inferred that the hypothesis holds good only for the important criteria where significant correlation exist. From the three sets of data analyzed (transport projects, water projects, combined data), we observe that 'Ease of Use' is the one common criteria with correlation coefficient value above 0.1 and level of significance less than 0.05 . Other criteria vary between data sets. This possibly points to limited possibility of common success criteria for different stakeholders for different type of projects. In line with Bannerman's views Success criteria is often guided by "..expectations of what theproject was to achieve and perceptions of whether it achieved them often vary among stakeholders"'[2]. Also, researchers like Baccarini and Nelson mentioned in their respective studies that "project success criteria should be specific to each project and that they should therefore be determined by stakeholders at the start of each project"'[11][29].

\section{E. Study Implications}

- Similar rating for project success by users and project professionals shows good knowledge level on infrastructure projects among users in Thiruvananthapuram. Moreover, higher success rating for transport sector with higher level of involvement and awareness supports this argument and suggests a possible relation and source of further study for multiple sectors.

- Major difference in relation of each success criteria with success rating among the transport and water sectors points to the fact that success criteria vary between sectors and based on type of projects. Further, this difference in a user context points towards the necessity for comprehensive needs assessment and user consultation during projects. Similar implications are reported from study of project managers also[30]

\section{CONCLUSION}

Comparison of success rating by stakeholders for Transport and Water sector projects revealed that success ratings are significantly different between the sectors with success rating for transport projects significantly higher than water projects. Evaluation of success rating by users when compared with project professionals showed that the ratings are similar.

Analysis of association between success rating and each success criteria resulted in four success criteria (Time, Budget, Expected Benefits and New Technology) showingsignificant correlationswhilethe remaining nine criteria has weak coefficients. Examination of correlations for individual sectors exposed that only seven criteria have significant correlations for water projects whereas in transport projects the five correlations are weak. Comparison of the transport and water sectors show that the correlation of success criteria to success rating is stronger in water sector projects than transport sector projects.

\section{ACKNOWLEDGMENT}

We thank the makers of statistical software JASP Ver 12.1 and LISREL 10.2 (Student Version) both of which is extensively used in the current analysis. A special thanks to Dr. ChandramohanAsan, Former Director, School of
Management Studies, College of Engineering, Trivandrum for review and value addition for this paper.

\section{REFERENCES}

1. S. Lipovetsky, A. Tishler, D. Dvir, \& A. Shenhar, The relative importance of project success dimensions. Research \& Development Management, $\quad 27 \quad$ (1997) 97-106. https://doi.org/10.1111/1467-9310.00047.

2. P. L. Bannerman, Defining Project Success: A Multi-Level Framework. (2008).

3. L. A. Ika, Project Success as a topic in Project Management Journals. Project Management Journal, (2009) 6-19. https://doi.org/10.1002/pmj.

4. R. Müller \& K. Jugdev, Critical success factors in projects. International Journal of Managing Projects in Business, 5 (2012) 757-775. https://doi.org/10.1108/17538371211269040.

5. B. N. Baker, D. Fischer, \& D. C. Murphy, Multiple Determinants of Project Success and Failure. (1974).

6. J. K. Pinto \& D. P. Slevin, Project success: Definition and Measurement Techniques. Project Management Journal, 19 (1988) 67-73

7. R. Atkinson, Project management: cost time and quality two best guesses and a phenomenon, it's time to accept other success criteria. International Journal of Project Management, 17 (1999) 337-342. https://doi.org/10.1016/S0263-7863(98)00069-6.

8. 8. A. de Wit, Measurement of project success. International Journal of Project Management, 6 (1988) 164-170. https://doi.org/10.1016/0263-7863(88)90043-9.

9. A. K. Munns \& B. F. Bjeirmi, The role of project management in achieving project success. International Journal of Project $\begin{array}{llll}\text { Management, } & \mathbf{1 4} & \text { (1996) }\end{array}$ https://doi.org/http://dx.doi.org/10.1016/0263-7863(95)00057-7.

10. K. Jugdev \& J. Thomas, Rethinking Project Management: Old Truths and New Insights. 7 (2001) International Project Management Journal.

11. D. Baccarini, The Logical Framework Method for Defining Project Success. Project Management Journal, Volume 30 (1999) 25-32. https://doi.org/10.1086/250095.

12. T. Cooke-Davies, The "real" success factors on projects. International Journal of Project Management, 20 (2002) 185-190. https://doi.org/10.1016/S0263-7863(01)00067-9.

13. R. Joslin \& R. Müller, The impact of project methodologies on project success in different contexts. PMI Research and Education Conference, July 28-29, 2014, (2014) 1-29. https://doi.org/10.1108/IJMPB-03-2015-0025.

14. J. Wateridge, How can IS/IT projects be measured for success? International Journal of Project Management, 16 (1998) 59-63. https://doi.org/10.1016/S0263-7863(97)00022-7.

15. B. A. Hussein, Factors influencing project success criteria Proceedings of the 2013 IEEE 7th International Conference on Intelligent Data Acquisition and Advanced Computing Systems, IDAACS 2013, 20 (2013) 566-571. https://doi.org/10.1109/IDAACS.2013.6662988.

16. A. J. Shenhar \& R. M. Wideman, Improving PM: Linking Success Criteria to Project Type. Creat. Can. Advant. through Proj. Manag. (1996). https://doi.org/10.1007/BF00043865.

17. A. J. Shenhar, D. Dvir, O. Levy, \& A. C. Maltz, Project success: A multidimensional strategic concept. Long Range Planning, 34 (2001) 699-725. https://doi.org/10.1016/S0024-6301(01)00097-8.

18. L. Laroche, D. Ph, \& P. Eng, Managing Cross-Cultural Differences in International Projects. Engineering Dimensions, (1998).

19. S. Kothandath, Project Success Criteria Preferences. IUJ Journal of Management, 6 (2018) 73-77.

20. R. Joslin \& R. Müller, Relationships between a project management methodology and project success in different project governance contexts. International Journal of Project Management, 33 (2015) 1377-1392. https://doi.org/10.1016/j.ijproman.2015.03.005.

21. B. Hussein, S. Ramazani, \& S. H. Kazemi, Preliminary investigation of project success criteria in Norway. Proceedings of the 6th IEEE International Conference on Intelligent Data Acquisition and Advanced Computing Systems: Technology and Applications, $\begin{array}{llll}\text { IDAACS'2011, } & \mathbf{2} & \text { (2011) }\end{array}$ https://doi.org/10.1109/IDAACS.2011.6072906. 
22. D. Dvir \& A. Shenhar, Book Summary - The Diamond Approach to Succesful Growth and Innovation. Reinventing Project Management, (2007) 5. https://doi.org/10.1111/j.1540-5885.2008.00327_2.x.

23. A. Subiyakto, A. R. Ahlan, M. Kartiwi, \& H. T. Sukmana, Measurement of information system project success based on perceptions of the internal stakeholders. International Journal of Electrical and Computer Engineering, 5 (2015) 271-279.

24. G. D. Israel, Determining Sample Size. University of Florida, IFAS Extension, PE0D6 (1992) 1-5. https://doi.org/10.4039/Ent85108-3.

25. JASPTeam, JASP (Version 0.12.2)[Computer software]. (2020).

26. U. Olsson, F. Drasgow, \& N. J. Dorans, The polyserial correlation

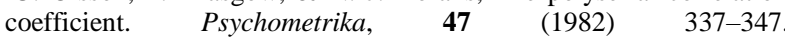
https://doi.org/10.1007/BF02294164.

27. D. Jöreskog, K.G. \& Sörbom, LISREL 10 for Windows [Computer software]. Skokie, IL: Scientific Software International, Inc. (2018).

28. Ramana PV, Mood 's Median Non Parametric Hypothesis Test. (2020) $1-9$.

https://sixsigmastudyguide.com/moods-median-non-parametric-hypot hesis-test/ (accessed June 16, 2020).

29. R. R. Nelson, PROJECT RETROSPECTIVES: EVALUATING PROJECT SUCCESS, FAILURE, AND EVERYTHING IN BETWEEN. MIS Quarterly Executive, 4 (2005) 361-372.

30. R. Müller \& R. Turner, The Influence of Project Managers on Project Success Criteria and Project Success by Type of Project. European Management Journal, $25 \quad$ (2007) 298-309. https://doi.org/10.1016/j.emj.2007.06.003.

\section{AUTHORS PROFILE}

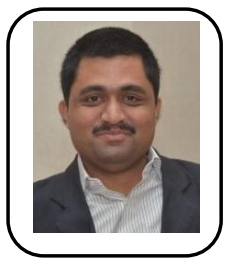

Sarosh Kothandathis research scholar at Faculty of Management Studies, ICFAI University Jharkhand pursuing his Ph.D. in Project Management with specific focus on success of public infrastructure projects. The current paper is aslice of the continuing research on water and transport projects in Thiruvananthapuram. Sarosh completed post-graduation in hydraulics engineering from Kerala University, MBA in International Business from ICFAI University,Tripura after graduation in Civil engineering and as professional consultant helped manage several water infrastructure programs in multiple geographies. Sarosh is a fellow of Institution of Engineers (India) and holds memberships with other prestigious engineering bodies like ASCE, IWWA, IAHS etc.

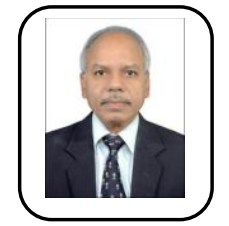

Dr. Hari Haranis Adjunct Professor at ICFAI University Jharkhand, Ranchi, Management Consultant and Trainer and was GM (HRD) of SAIL Management Training Institute. He did B. Tech. (Mech. Engg.) from IIT-BHU, Master of Business Management from FMS, $\mathrm{BHU}$ and Ph.D.(Management) from BIT, Mesra (Ranchi). Authored the book on 'Corporate Entrepreneurship- Strategic Imperative for Growth', 4 edited books on management topics, Special contributions in International and National Conferences and has been in Editorial Board of management journals 'Growth' of SAIL, MTI, 'Alternative' of BIT, Mesra. Research work of Ph.D. aspirants in marketing and entrepreneurship and projects of MBA students from India and abroad have been guided by him. He is member of Research Board of ICFAI University, Jharkhand, Life member of leading professional bodies operating in the fields of Engineering, Management and Training \& Development. He has been nominated by Hon'ble Chancellor (Hon'ble Governor of Jharkhand) as member in the Senate of Ranchi University as person of scholarly pursuits. 